\title{
Internalism, Externalism, and the KK Principle
}

\section{Alexander Bird $^{1}(\mathbb{D}) \cdot$ Richard Pettigrew $^{2}$}

Received: 3 April 2018 / Accepted: 3 October 2019 / Published online: 16 November 2019

(c) The Author(s) 2019

\section{Abstract}

This paper examines the relationship between the KK principle and the epistemological theses of externalism and internalism. In particular we examine arguments from Okasha (Analysis 73(1):80-86, 2013) and Greco (J Philos 111(4):169-197, 2014) which deny that we can derive the denial of the KK principle from externalism.

\section{Introduction}

This paper examines the relationship between the KK principle and the epistemological theses of externalism and internalism. There is often thought to be a very close relationship between externalism and the rejection of the KK principle, on the one hand, and between internalism and its acceptance, on the other. How strong are the connections? The stronger proposals are: externalism entails the denial of the KK principle; internalism entails the truth of the KK principle. We consider two problems for these proposals. First, Okasha (2013) argues that to derive such connections one must commit the fallacy of substituting extensionally equivalent but intensionally distinct propositions in intensional contexts. Secondly, Greco (2014) argues that his externalist account of knowledge in fact entails the KK principle, so it cannot be that externalism entails its negation. We argue that we should reject Greco's argument and that connections between internalism, externalism, and the KK principle can be found that do not commit the intensional fallacy.

$\triangle \quad$ Alexander Bird

Alexander.Bird@kcl.ac.uk

Richard Pettigrew

Richard.Pettigrew@bristol.ac.uk

1 Department of Philosophy, King's College London, Philosophy Building, Strand, London WC2R 2LS, UK

2 Department of Philosophy, University of Bristol, Cotham House, Cotham Hill, Bristol BS6 6JL, UK 
In its simplest formulation the KK principle asserts that, if a subject knows $p$, then the subject knows that she knows $p$. In symbols:

$$
K p \rightarrow K K p
$$

Or with greater generality:

$$
\square \forall s \forall p\left(K_{s} p \rightarrow K_{s} K_{s} p\right)
$$

where $K_{s} p$ means subject s knows proposition $p$. Such a formulation is vulnerable to the objection that a subject may know some proposition yet not have even considered whether they know it; if belief is a necessary condition on knowledge, then such a subject may know without knowing that they know. So the KK principle may be weakened to assert that a knower is in a position to know that she knows. And so a rough reformulation says that a subject who knows $p$ and believes that she knows $p$ also knows that she knows $p .{ }^{1}$ In symbols:

$$
K p \& B K p \rightarrow K K p
$$

(weak KK)

Or, with greater generality:

$$
\forall s \forall p\left(\left(K_{s} p \& B_{S} K_{s} p\right) \rightarrow K_{S} K_{s} p\right)
$$

where $B_{s} p$ means subject s believes proposition $p .^{2}$

We start by adopting the assumption that an account of knowledge can be represented as a conjunction of three conditions:

$$
K p \equiv(B p \& p \& X p) \quad \text { (the analysis of knowledge) }
$$

where $X$ is a propositional function that takes $p$ as an argument, and returns $X p$, which is a proposition that provides whatever the given account of knowledge claims must be added to true belief in $p$ to ensure knowledge in $p$-note that $X p$ may entail $B p$ or $p$. The idea that knowledge may be informatively analysed as a conjunction of necessary conditions that are jointly sufficient may well be a fiction. But for present purposes it is a useful fiction, with which we can dispense in due course. The analysis of knowledge is supposed to be a necessary truth that holds for all subjects and all

\footnotetext{
1 This weakening of KK is intended to handle the counterexample of a subject who has not considered whether she knows $p$. It may also handle the more interesting counterexample raised by Conee (2016) concerning a subject who has considered whether she knows $p$ but does not believe that she does because she falsely but rationally believes that knowledge is very demanding (for example by believing a false analysis of knowledge). Conee thinks that such a subject is not in a position to know that she knows, but that is not entirely clear to us.

2 An alternative that retains the $\mathrm{S} 4$ version of $\mathrm{KK}$ would be to understand $K_{S} p$ as subject $s$ is in a position to know proposition $p$ throughout. This requires understanding the analysis of knowledge in what follows in a similar way, i.e. dropping the belief condition on knowledge in the arguments of Sect. 2.1 etc.
} 
propositions. So we will also articulate the analysis in the following form:

$$
\square \forall \forall p\left(K_{s} p \equiv\left(B_{s} p \& p \& X_{s} p\right)\right) \quad \text { (the analysis of knowledge) }
$$

where $X_{s} p$ means subject s satisfies the condition $X$ with respect to $p$.

We define externalism as the claim that for some necessary condition on knowledge, $\Phi$, it is possible for some subject to know some proposition and believe that she knows it without knowing that $\Phi$ holds of it with respect to her. ${ }^{3}$ In symbols:

$$
\diamond \exists s \exists p\left(K_{s} p \& B_{S} K_{s} p \& \neg K_{S} \Phi_{s} p\right)
$$

(externalism)

In particular, an analysis of knowledge in the form given above will be an externalist analysis of knowledge just in case it is possible that there be a subject $s$ and proposition $p$ such that $s$ knows $p$ and $s$ believes that $K_{s} p$, but $s$ does not know $X_{s} p$. Internalism is the denial of externalism. We acknowledge that definitions of externalism and internalism are themselves debated. We nonetheless hold that our definitions capture a central commitment of many approaches to this distinction-details of the relationship of our definitions to other definitions and the consequences for our argument are a topic for future discussion. ${ }^{4}$ (As we will see later, a key conclusion of this paper, is that we need to supplement this definition to exclude analyses that while intuitively externalist are nonetheless internalist by their own lights.)

When a subject $s$ is in the position of knowing some proposition $p$ but not knowing that $X_{s} p$ holds, then we say that such a subject is a witness to externalism. So externalism is the claim that it is possible for some subject, with respect to some proposition, to be a witness to externalism. Internalism is the denial of externalism, so it is the claim that it is not possible for any subject to be a witness to externalism, with respect to any proposition.

Why investigate the connections between these two pairs of claims: internalism and externalism, on the one hand, and KK and its negation, on the other? Partly, of course, because much has been made of the connections, as Okasha's extensive list of extracts from the literature shows. But partly, as well, because it is always philosophically productive to investigate biconditional claims. If we can establish (Internalism iff KK), or equivalently, (Externalism iff $\neg \mathrm{KK}$ ), then we can convert any argument for internalism into an argument for $\mathrm{KK}$, or any argument against KK into an argument

\footnotetext{
3 Arguably we should require that the condition in question is not merely necessary but essential to knowledge, to avoid trivially necessary conditions, such as any necessary truth. Our argument will not be sensitive to this choice.

4 Our definition agrees with Nozick's account of internalism according to which knowledge requires knowledge of all the preconditions of knowledge (Nozick 1981, 281). We believe that is also aligns with the accessibilism of BonJour (1980), with respect to justification, according to which justification depends only on states the subject can reflectively access-though we cannot defend that belief here. The internalismexternalism debate is often focussed on justification rather than knowledge. Our discussion, we believe, can readily be extended to cover the relationship between internalism about justification and KK, since the existence or otherwise of a condition $\Phi$ on knowledge will be the same matter as the existence or otherwise of such a condition on justification. Note in particular that our account of externalism does not make truth an external condition. on the assumption that knowing $p$ entails knowing $p$ is true. For then it is not possible to know $p$ without knowing $p$ is true.
} 
for externalism. It turns out that we cannot establish the biconditional. But we do get an entailment in one direction, from externalism to the denial of KK (or, equivalently, from KK to internalism).

\section{Externalism, KK, and the Intensional Fallacy}

\subsection{Okasha's Reconstruction of the Standard Argument}

Externalist epistemologists often argue from their externalism to the falsity of the KK principle. Okasha has gathered numerous quotations from such epistemologists to demonstrate the point. ${ }^{5}$ He then goes on to show that the argument from externalism to $\neg \mathrm{KK}$ that provides the natural interpretation of these quotations is fallacious. The argument Okasha $(2013,82)$ reconstructs is as follows: ${ }^{6}$

(1) $K p \& B K p \& \neg K X p$

(assumption)

(2) $K p \equiv(B p \& p \& X p)$

(the analysis of knowledge)

(3) $(K p \& B K p) \rightarrow K K p$

(weak KK, assumed for RAA)

(4) $K K p$

(5) $K(B p \& p \& X p)$

(6) $K X p$

(7) $\neg((K p \& B K p) \rightarrow K K p)$

What licenses assumption (1) is that the analysis of knowledge, (2), is intended to be an externalist one. We therefore consider a subject who is a witness to externalism. For this witness, the assumption of the KK principle leads to a contradiction. Since the KK principle is supposed to be a necessary proposition, this witness to externalism also constitutes a counterexample to the KK principle.

However, as Okasha points out, the inference from (2) and (4) to (5) involves substituting necessary equivalents within an intensional operator, $K$. Such substitutions are, however, fallacious. We cannot infer from the fact that Nadia knows that Stokely Carmichael was taught by Toni Morrison, together with the fact that, necessarily, Stokely Carmichael was taught by Toni Morrison iff Kwame Touré was taught by Toni Morrison (because Stokely Carmichael is Kwame Touré), that Nadia knows that Kwame Touré was taught by Toni Morrison. Thus, the argument fails.

\subsection{An Alternative Route?}

One might think that there is an alternative route to establishing that externalism leads to denial of the KK principle, using the standard philosopher's tool of eliciting

\footnotetext{
5 Okasha (2013, 80-1) cites Williams (1995, 96), Dretske (2004, 176), Bird (1998, 220), Pagin (2012, 881), Schantz (2004, 9) and Hemp (2006).

${ }^{6}$ Okasha's original reconstruction of the argument concerns the KK principle, rather than the weak KK principle formulated above and used in the argument below. But nothing of substance hangs on that.
} 
intuitions about a counterfactual set of circumstances. One would construct the story so that it is intuitively clear that a particular set of externalist conditions for knowledge (e.g. reliably formed true belief) is satisfied by the subject's first order belief, but clear also that their second order belief about their first order state does not satisfy those conditions. For example a subject $s$ believes $p$ as a result of consulting a carefully compiled and entirely factually correct encyclopaedia (all $s$ 's first order beliefs are generated in this way); $s$ also believes that the encyclopaedia is reliable, but only as a result of wishful thinking. So one might conclude that this is a case where, by the lights of reliabilism, the subject's first order belief is knowledge, but their second order belief (that they know) is not.

One must be careful in deploying such an argument.

First, if sound, it would show only that a particular version of externalism (e.g. reliabilism) entails the falsity of the KK principle, not than all externalist analyses have this consequence. Indeed, as we discuss in the next section there are analyses of knowledge that, on the face of it, are externalist but which in fact themselves entail KK.

Secondly, such an argument still needs to take care to avoid falling foul of Okasha's criticism. It needs to be shown that $s$ has not formed the belief 'I know that $p$ ' reliably. So our judgment that $s$ does not know that she knows $p$ is based on two judgments that we make: (1) our judgment that she has used an unreliable method-namely, wishful thinking-to establish her second-order belief that her first-order belief in $p$ was reliably formed; and (2) our judgment that any second-order belief that she formed concerning whether her first-order belief in $p$ counts as knowledge must have been formed by the same unreliable method. But judgment (2) is based on the intensional fallacy that Okasha identifies. While it is perfectly possible that $s$ came to believe that her first-order belief $p$ was reliably formed by an unreliable method, it could simultaneously be true that $s$ came to believe that her first-order belief $p$ is knowledge by a reliable method. Perhaps she came to believe that the encyclopaedia is reliable by wishful thinking, but came to believe that she knows $p$ by consulting a highly reliable epistemic guru.

Thirdly, there may in any case be a route to second-order knowledge that satisfies the relevant externalist analysis of knowledge if the first order beliefs do. Consider a subject $s$ who forms all her first order beliefs by reliable means, and who follows the following rule for forming second-order beliefs: 'If I have a first order belief $p$, then believe that I know that $p$ ' (arrogance). Subject $s$ may have no evidence for the reliability of arrogance, but that of course is irrelevant for the reliabilist. If $s$ does not misidentify her first order beliefs, then her second order beliefs will be reliably formed, since it is true according to reliabilism that all the subject's first order beliefs are knowledge. And so according to reliabilism, the subject's second order beliefs (e.g. the belief that she knows $p$ ) are all true. ${ }^{7}$ This reinforces the preceding point-a subject can have second order knowledge, according to reliabilism, without any true (or false) beliefs at all regarding the reliability of the means by which their first order beliefs are formed.

\footnotetext{
7 The soundness of this argument may depend on precisely how one articulates reliabilism and individuates methods. Nonetheless, this shows that the 'alternative' route does not constitute a straightforward argument for the rejection of KK from externalism-matters are more subtle here than is often supposed.
} 
This does not prove that no story can be constructed for a specific externalist analysis of knowledge that elicits clear intuitions that there is first order knowledge (by that analysis) but not second order knowledge while also avoiding the second and third pitfalls. But constructing that story is not trivial, nor have we seen it done.

\section{Do Some Versions of Externalism Entail KK?}

Daniel Greco (2014) argues that his account of knowledge entails the KK principle yet it is also externalist. A fortiori, externalism cannot entail the negation of the KK principle. It would also seem to suggest that there is no interesting connection between internalism or externalism on the one hand and KK on the other.

In our view this is mistaken. We shall see that some accounts of knowledge look to be externalist and do entail KK. But they are poor accounts of knowledge. In particular they make knowledge too easy. And that's why they entail KK. On inspection we can see that although 'intuitively' they are externalist accounts, by their own lights they are internalist accounts. This is true of Greco's account of knowledge.

\subsection{A Simple Externalist Account of Knowledge that Entails KK}

Let MM be the following form of externalism:

$$
K p \equiv(B p \& p \& M p)
$$

where $M p$ is the proposition Mars has two moons, regardless of what the proposition $p$ is. Thus, for any two propositions $p$ and $q$, we have $M p \equiv M q$. That is, $M$ is a constant propositional function. Being a constant function, it is independent of $p$, and so it generates the same third condition for $K p, K K p, K K K p, \ldots$ In particular, $M p \equiv M K p$.

Now, note that MM is externalist according to the criterion proposed above. That is, it is intuitively possible for there to be a witness to externalism in this form: a subject who knows some proposition, who believes that they know that proposition, but fails to know a necessary condition on knowledge, viz. that Mars has two moons. Formally, this witness is a subject $s$ who for a proposition $p$ is such that $s$ knows $p\left(K_{s} p\right), s$ believes that $s$ knows $p\left(B_{S} K_{s} p\right)$, but $s$ does not know that $M_{S} p$ holds $\left(\neg K_{S} M_{s} p\right)$.

(Furthermore, such a subject must believe $K_{s} p$ but not believe $M_{s} p$, for if she believes $M_{s} p$, then all the conditions for knowing $M_{s} p$ would be satisfied, namely, $B_{s} M_{s} p \& M_{s} p \& M_{s} M_{s} p$, so she would know $M_{s} p$ and she would not witness the externalism of MM. Thus, we must assume that this subject cannot know MM, for if she were to know MM whilst believing $K_{s} p$, then she would believe $M_{s} p$, since $M_{s} p$ is one of the conjuncts in the analysis of $K_{s} p$ provided by MM. This will become important later. In Sects. 4.1 and 4.2, we will see that, if we restrict our attention to externalist analyses on which it is possible for the same subject to witness the externalism of the analysis and also to know the analysis in question, then we can fill 
the gap identified by Okasha in the argument from an externalist analysis to the denial of KK.)

For now, we have the following justification of the weakened version of KK based on MM:

(1) $K p \& B K p$

(2) $M p \equiv M K p$

(3) $K p \equiv(B p \& p \& M p)$

(4) $K p \rightarrow M K p$

(5) $B K p \& K p \& M K p$

(6) $K K p$ (assumption)

(since $\mathrm{M}$ is constant)

(4, MM)

Here we have derived the following from MM:

$$
(K p \& B K p) \rightarrow K K p
$$

(weaker KK principle)

This is the weak version of the KK principle that isn't vulnerable to the obvious counterexamples to KK that come from noting that someone might know $p$ without believing that they know $p$. Note that this argument does not suffer from any intensional fallacy because the substitution that yields $K K p$ from the analysis of knowledge involves substituting the first, outer occurrence of $K$, whereas the fallacy identified by Okasha concerns the second, inner occurrence.

So our weakened version of the KK principle follows from MM. And MM is an externalist analysis of knowledge. So externalism does not entail the denial of KK.

In fact, this is a particular instance of a more general fact that follows from MM, and which illustrates the shortcomings of externalist proposals that are similar to MM. It follows from MM that, in the actual world, where Mars does indeed have two moons, a subject knows any proposition that they truly believe. And, of course, this will be the case for any analysis of knowledge $K p \equiv(B p \& p \& X p)$ where $X$ is a constant propositional function whose single propositional value is true at the actual world. That is, MM makes knowledge too easy to come by. It is hardly surprising, then, that the KK principle is satisfied.

\subsection{Greco's Argument for KK}

The case of MM appears to show that we cannot hope for a general argument from externalism to the denial of KK (although we shall revisit this later). Of course, no externalist epistemologist would accept MM or anything like it as a plausible candidate for an analysis of knowledge-plausible external conditions are those that articulate some kind of relation between the world and the subject's belief. However, some 
externalists do propose prima facie plausible analyses of knowledge that are intuitively externalist on our definition and which do entail $\mathrm{KK}^{8}{ }^{8}$

As an example, we consider Greco's (2014) analysis of knowledge and argument for KK based on that analysis. Greco's analysis is indeed intuitively externalist. And the argument for $\mathrm{KK}$ is valid. In this section we argue that the analysis is unsatisfactory and the argument for KK makes question-begging and questionable assumptions about the character of the 'normally' ('in normal conditions') operator. However, the important conclusion, as regards the overall argument of this paper, is that Greco's analysis shares a significant shortcoming with MM. Both analyses make knowledge too easy-hence the entailment of $\mathrm{KK}$ is no surprise. And, in particular, that means that the supposedly external condition ' $X p$ ' is known to the subject who knows that $p$. Hence, although intuitively externalist, Greco's analysis is internalist by its own lights. This point we discuss in the next section.

Greco's analysis centers on the idea that knowing is a matter of carrying information. A state $X$ carries the information that $p$ just in case, when conditions are normal, $X$ obtains only when $p$ is true, and conditions are normal. The resulting account of knowledge is as follows:

$s$ knows $p$ iff

(1) $s$ believes $p$;

(2) $p$;

(3) conditions are normal;

(4) $s$ is in a state $X$ such that, in normal conditions, if $s$ is in $X$, then $p$.

(5) $s$ 's being in state $X$ causes or constitutes $s$ 's belief $p$.

Greco maintains that this is an externalist analysis. On this account, the condition $X_{s} p$ in the analysis of knowledge is the conjunction of (3), (4), and (5). Intuitively, this is externalist-it is possible that there is a subject who knows $p$ and believes that she knows $p$ without knowing that (3), (4), and (5) hold. For she may not even believe that (3), (4), and (5) hold, because she does not know the correct analysis of knowledge. Even if she does believe (3), (4), and (5) it is implausible that she must know these because, intuitively, she might not know that conditions are normal or that her belief $p$ was caused or constituted by the state $X$.

In order to simplify the discussion, Greco idealizes by pretending that, whenever conditions (3) and (4) are met, this causes or constitutes $s$ 's belief $p-$ so (3) and (4) are taken to entail (5) and (1). While this avoids having to worry about objections to KK that turn on the failure of belief to iterate (as we have also sought to do), it also removes a point on which the opponent of KK might wish to base an argument, viz. the subject's sensitivity to the causal/constitutive relation between the state $X$ and their belief. Nonetheless, we will proceed as Greco does. Note also that (3) and (4) also entail (2). So we can take Greco's analysis of knowledge to be just the conjunction of (3) and (4):

\footnotetext{
8 We discuss here the argument from Greco (2014) and refer also to a similar one from Stalnaker (2015) which both see knowledge as information-carrying. Das and Salow (2018) put forward a different argument for KK that also claims to be consistent with externalism, which we do not consider here.
} 
$K_{s} p \equiv s$ is in a state $X_{S}$ such that $\square_{N}\left(X_{S} \rightarrow p\right) \& N$

(Greco's analysis)

where ' $N$ ' symbolizes 'conditions are normal' and ' $\square_{N} p$ ' symbolizes 'in all normal worlds $p$ '.

We saw that MM entails KK because $M$ is a constant propositional function and so, $M p \equiv M K p$, for any $p$; hence from $M p$ we can infer $M K p$, as is used in line 4 of the proof of KK from MM. $X_{s}$ is not a constant propositional functionthere are $p, q$ such that $X_{s} p \neq \equiv X_{s} q$-but it is idempotent-that is, $X_{s} p \equiv X_{s} X_{s} p$ (where ' $X_{s} p$ ' symbolises ' $s$ is in a state $X_{s}$ such that $\square_{N}\left(X_{s} \rightarrow p\right.$ )'). We will see that Greco's argument treats $N$ as a constant function (we regard that as controversial). So $X_{s} p \& N$ is equivalent to $X_{S} X_{s} p \& N$, i.e. $K_{s} p \equiv K_{s} K_{s} p$. Let us see how the proof proceeds.

We start with two lemmas.

First lemma Suppose $s$ is in a state, $X_{s}$, such that normally, when $s$ is in that state, $p$. Then $s$ is in a state, namely $X_{s}$, such that when $s$ is in that state, then normally, when $s$ is in that state, $p$. We can add 'normally' to the preceding sentence without loss: $s$ is in a state, namely $X_{s}$, such that normally when $s$ is in that state, then normally, when $s$ is in that state, $p$. Putting this together, a bit more formally: when $s$ is in a state $X_{S}$ such that $\square_{N}\left(X_{S} \rightarrow p\right)$ then $s$ is in a state (namely $\left.X_{s}\right)$ such that $\square_{N}\left(X_{S} \rightarrow\right.$ $\left.\square_{N}\left(X_{s} \rightarrow p\right)\right)$, i.e.

$s$ is in a state $X_{S}$ such that $\square_{N}\left(X_{S} \rightarrow p\right) \rightarrow$

$s$ is in a state $X_{s}$ such that $\square_{N}\left(X_{s} \rightarrow\left(s\right.\right.$ is in a state $X_{s}$ such that

$\left.\left.\square_{N}\left(X_{s} \rightarrow p\right)\right)\right)$

Second lemma $\square_{N}(N)$ is trivially true, so any proposition $P$ within the scope of $\square_{N}$ may be substituted by $P \& N$; i.e. for any $P \square_{N}(P)$ entails $\square_{N}(P \& N)$

The proof now proceeds:

(1) $K_{s} p$

(assumption)

(2) $s$ is in a state $X_{S}$ such that $\square_{N}\left(X_{S} \rightarrow p\right)$

(1, Greco's analysis)

(3) $N$

(1, Greco's analysis)

(4) $s$ is in a state $X_{s}$ such that $\square_{N}\left(X_{s} \rightarrow\right.$ (s is in a state $X_{s}$ such that $\left.\left.\square_{N}\left(X_{s} \rightarrow p\right)\right)\right)$

(2, first lemma)

(5) $s$ is in a state $X_{s}$ such that $\square_{N}\left(X_{s} \rightarrow\right.$ (s is in a state $X_{s}$ such that

$$
\left.\left.\square_{N}\left(X_{S} \rightarrow p\right) \& N\right)\right)
$$

(4, second lemma)

(6) $s$ is in a state $X_{s}$ such that $\square_{N}\left(X_{S} \rightarrow K_{s} p\right)$

(5, Greco's analysis)

(7) $s$ is in a state $X_{s}$ such that $\square_{N}\left(X_{s} \rightarrow K_{s} p\right) \& N$

(8) $K_{s}\left(K_{s} p\right)$

(7, Greco's analysis)

(9) $K_{s} p \rightarrow K_{s}\left(K_{s} p\right)$

While Greco's analysis doesn't make knowledge quite as easy to come by as MM makes it, it does make knowledge too easy: if a subject knows any proposition at all, 
this immediately entails that conditions are normal. And thus, for any state that she is in, and any proposition that holds normally when she is in that state, she knows that proposition, even if she has no reason to rule out abnormal conditions. Let's suppose, for instance, that Aneri is travelling in Italy. She looks at the clock in Milan's central train station; it reads 12:05 p.m. Normally, though by no means invariably, the station clocks in Italy work well and reliably show the correct time. However, this one doesn't—it's currently being fixed. But, by luck, Aneri looks up to read it at exactly 12:05 p.m., the time at which it has stopped. According to Greco's analysis, as long as Aneri knows something - that she has hands, for instance-then conditions are normal, and since she's in a state that normally indicates that the time in 12:05 p.m., she knows that it is 12:05 p.m. Thus, on Greco's analysis, as on the MM analysis, knowledge is easy. So it is little surprise that we can establish the KK principle.

An appropriate response to this easy knowledge problem is to relativise normal conditions either to the proposition in question or the process by which the subject's belief in that proposition was formed..$^{9}$ Let's consider proposition-relative normality first. ${ }^{10}$ On this proposal, Aneri's conditions are normal for knowing she has hands but not normal for knowing the time by looking at the clock. This, however, renders the proof of KK invalid. Let ' $N_{p}$ ' denote the proposition that conditions are normal relative to the proposition $p$. Now line 3 of the proof must read ' $N_{p}$ ', whereas to make the inference to line 5 , it would have to read ' $N_{K_{s} p}$ '. So the revised proof with relativised normality conditions is valid only if it can also be shown that normal conditions for $p$ are the same as or a subset of the normal conditions for $K_{s} p$-that is, only if $N_{p} \rightarrow N_{K_{s} p}$. In order to make his account quite general, Greco declines to say much about what makes conditions normal, and so we are not in a position to see how such an argument might proceed. However, it appears to us that any attempt to argue that $N_{p}$ entails $N_{K_{s} p}$ is likely to beg the question. One would expect normal conditions for stronger propositions to be more restrictive than normal conditions for the weaker propositions they entail. For example, in order to know that $p \& q$ one would need to meet the conditions for knowing $p$ and the conditions for knowing that $q$. Hence normal conditions for the conjunction must be normal for both the conjuncts, i.e. they must be a subset of the intersection of the two sets of normal conditions for the conjuncts. So the question of whether normal conditions for $K_{s} p$ are the same as or a subset of the normal conditions for $p$ is likely to turn on whether it is more demanding to know $K_{s} p$ than it is to know $p$. And that's just the point at question. Deniers of

\footnotetext{
9 Goodman and Salow (2018, 191-2) have recently developed a formal account of normality that is not binary but is ordered, and which they hold to support KK. It remains to be seen whether this account is immune to versions of the objections mounted here.

10 This response might be thought to be implied by Greco's contextualism, whereby a shift of context may change what counts as normal conditions. Greco uses this to explain why KK may often seem false although it is true, and why the safety principle seems true although it is false (Greco's analysis entails the falsity of safety, thereby rejecting Williamson's Williamson (1996) safety-based anti-luminosity argument against KK). But these are unrelated issues, since what determines context is the situation of the attributor of knowledge whereas what is needed to avoid the easy knowledge problem is relativizing normal conditions to the proposition believed by the subject.
} 
KK will say that it is more demanding; supporters will say that the demands are the same. $^{11}$

So the position is this. Greco's proof of KK takes normality to be a constant function. While the proof is valid, this also makes knowledge far too easy. The latter can be avoided by relativising normal conditions. But then the proof of $\mathrm{KK}$ is not valid as it stands. A further lemma is needed that shows that normal conditions when relativised to any proposition $p$ include the conditions that are normal for $K_{s} p$. And the argument for that lemma is likely to beg the very question at issue, whether the conditions under which $s$ knows that $p$ include the conditions under which $s$ knows that $K_{s} p$.

We have demonstrated the latter point for relativising normal conditions to the proposition in question. It holds equally when we consider relativising normal conditions to the process by which the subject came to believe the proposition. ${ }^{12}$ Thus, for instance, if Aneri believes that she has hands via proprioception, and believes that the time is $12: 05$ p.m. via vision, then the fact that she knows she has hands only entails she's in a normal world with respect to the process of proprioception; it does not entail she is in a normal world with respect to vision. Thus, the inference from her knowledge that she has hands and her true belief that it is 12:05 p.m. to her knowledge that it is 12:05 p.m. is blocked. If we relativise normality in this way, what becomes of Greco's argument for KK? In order for that argument to go through, we must assume that normality relative to the process that produced the subject's belief in $p$ entails normality relative to the process that produced her belief in $K_{S} p$.

It will not generally be the case that conditions normal for the process by which $s$ comes to believe that $p$ are also normal for the process by which $s$ comes to believe that $s$ knows that $p$. For instance, I might come to believe that it is raining by looking out the window, while I come to believe that I know it is raining by some combination of introspection, attending to the testimony of others about my beliefs and evidence, and reading Greco's paper to obtain a correct analysis of knowledge. And it is clear that there are worlds in which my vision is functioning normally, but these other processes are not. However, what we are concerned with is whether by knowing that $p, s$ is thereby in a position to know that she knows that $p$. (Our weak KK is an inexact proxy for that idea.) So the question is this: is there some means of forming a belief that $K_{s} p$ that is always available to $s$ and for which normal conditions are the same as for her belief that $p$ ?

One might think that, from Greco's perspective, there could be-it might be that the very process that brings about the belief that $p$ can bring about the belief in the propositions $K_{s} p, K_{s} K_{s} p$, and so on. In that case, normality relative to the process that produced $p$ would appear to entail normality relative to the process that produced $K_{s} p$, since they are the same process! Again, though, there is a problem. For on looking at a piece of cloth one might come to believe both that it is red and that it is scarlet. There will be conditions under which one knows that the cloth is red but does not know that

11 Carter (2018) also draws attention to the role of the normality operator in Greco's proof, noting that the proof requires $N$ to satisfy the $\mathrm{S} 4$ axiom: $N p \rightarrow N N p$. Carter gives very plausible reasons for thinking that it is false that normality iterates.

12 Greco himself suggests this amendment to his analysis briefly in a footnote, where he also claims that his argument for KK will still go through this amendment (Greco 2014, Footnote 35, 181). As we argue now, this is false. 
it is scarlet (there are lighting conditions under which the cloth is clearly red, but under which one might be mistaken as to whether it is scarlet or crimson). So it will have to be the case that normal conditions for the proposition 'the cloth is red' judged by vision are different from the normal conditions for the proposition 'the cloth is scarlet' also judged by vision. One might well think that the relationship between $K_{s} p$ and $p$ is similar in this regard to the relationship between 'the cloth is scarlet' and 'the cloth is red', requiring are more restricted range of conditions that are normal in relation to the first of each pair than in relation to the second. A defender of Greco's proof might deny this. As above, what will be at issue in such a dispute are just the considerations that are the focus of existing debates about the correctness of the KK principle.

In summary, Greco's proof of KK is in effect this. First step: as just seen, any state is such that if conditions are normal, the subject knows they are in that state. Second step: in the special case where the state is knowledge, that state entails, as discussed, that conditions are indeed normal. So the subject knows that the subject knows. As presented, Greco's argument is valid but it also means not only that the subject knows that she knows, she also many other things that we do not take her to know: knowledge is too easily come by on Greco's account. If this outcome is to be avoided, then the amended argument is invalid. ${ }^{13,14}$

\subsection{What is Externalism?}

The preceding section presented the following dilemma for Greco. Either one interprets 'normal conditions' as a constant function. In which case the proof of KK is valid. But then the account of knowledge is implausible: it makes knowledge too easy. Or we can relativise 'normal conditions', avoiding the easy knowledge problem. But then the proof is no longer valid without supplementation by a further premise (that normal conditions for $p$ are also normal conditions for $p$ ) that begs the question regarding KK.

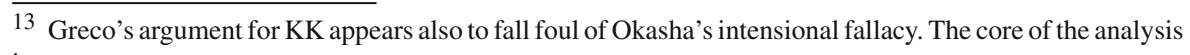
is:
}

$s$ is in a state $X$ such that $\square_{N}\left(X_{S} \rightarrow p\right)$

which Greco treats as an extensional context. His proof, principally the 'first lemma', requires that it is. More generally, he treats knowledge as being in an informational state with respect to $p$. And he says that if states A and B correlate then A carries whatever information B carries. So informational states are extensional. But if knowledge is intensional, then his analysis is also inadequate for that reason.

14 Stalnaker (2015) presents a model of knowledge, similarly based on the idea of knowledge as a state that carries information. A state $\mathrm{S}$ (of an entity that functions to carry information) carries the information that $\phi$ (knows that $\phi-\mathrm{K} \phi$ ) iff there is an environmental state $\mathrm{E}$ such that (1) when certain 'channel' conditions [c.f. Greco's normal conditions] hold, state S obtains iff E obtains; (2) S obtains; (3) the channel conditions obtain; and (4) E's obtaining entails that $\phi$. This entails KK because E obtains when S obtains (if the channel conditions obtain) and so $\mathrm{E}$ obtains only when $\mathrm{K} \phi$ (if the channel conditions obtain). So when $\mathrm{K} \phi \mathrm{S}$ is a state that obtains only when $\mathrm{K} \phi$ (if the channel conditions obtain), so $\mathrm{S}$ is also a state that obtains only when $\mathrm{S}$ is a state of information (knowledge) that $\mathrm{K} \phi$ (if the channel conditions obtain). Since if $\mathrm{K} \phi$ the channel conditions do obtain, then $\mathrm{KK} \phi$. As in Greco's argument, this depends on the channel conditions for carrying the information (knowing) that $\phi$ being the same as the channel conditions for carrying the information (knowing) that $\mathrm{K} \phi$. And those who reject the $\mathrm{KK}$ principle will reject that assumption. 
Nonetheless, the question on which we are focussed is whether externalism is consistent with the acceptance of KK. And if one seizes the first horn of the dilemma, that-Greco can maintain-still shows that an externalist analysis of knowledge is consistent with-indeed entails - the KK principle. While the analysis now looks less convincing, the issue is whether any analysis that is externalist is consistent with KK, not whether any analysis that is externalist and convincing is inconsistent with KK.

Matters, however, are subtle here. For the very weakness we identified in the analysis is what allows it to entail $\mathrm{KK}$ - the problem of easy knowledge makes knowing that one knows (too) easy. And, we argue, this same weakness raises a question about whether the analysis should be regarded as externalist after all.

We allowed, as Greco maintains, that his analysis is an externalist one, since intuitively a knower need not know that conditions are normal. By 'intuitively' here we are referring to our pre-theoretic intuitions about what we can know. On the other hand, Greco's analysis of knowledge itself tells us the opposite. For trivially, on Greco's analysis a subject knows that conditions are normal when they are normal. For any state a subject may be in is such that when conditions are normal then conditions are normal. Parallel comments may be made about MM. MM makes it the case that should the subject believe that Mars has two moons, then the subject fulfils MM's conditions for knowing that Mars has two moons. Hence in both cases should the subject know anything, the subject is in a position to know that the additional condition $X p$ is fulfilled. So while both analyses are intuitively externalist, they themselves have the consequence that they are internalist. That itself is a reason for regarding the analyses as unsatisfactory.

This means that the description 'externalist' of an analysis of knowledge is ambiguous. An analysis of knowledge may be regarded as externalist if:

(a) It is intuitively possible for a subject to satisfy the analysis and to be a witness to externalism;

or if:

(b) It is possible by the lights of the analysis itself for a subject to satisfy the analysis and to be a witness to externalism

Let us call an analysis weakly externalist if it satisfies (a) but not (b) while an analysis is strongly externalist if it satisfies both (a) and (b).

If we are to consider the relationship between externalism and the denial of the KK principle, we should look only at accounts of knowledge that are strongly externalist, and exclude those such as MM and Greco's analysis that are only weakly externalist. If an analysis include a condition $X p$ that is intuitively externalist yet which the analysis itself says is internalist, then we cannot expect that analysis to give us insight into the relationship between externalism and the denial of KK or between internalism and its acceptance. 


\section{Amending the Connections Between Externalism, Internalism and KK}

If it were indeed the case that versions of externalism (MM, Greco's analysis) in fact entail KK, then we ought to conclude that there are no interesting connections between externalism and denying KK or between internalism and affirming KK. However, those accounts are only weakly externalist - they turn out to be internalist after all, if we focus on what they themselves say about knowledge.

In this section we argue that we can recover informative connections if we focus on what the content of the correct account of knowledge is (whatever that may be), and ask what follows if the subject knows the correct account. This way we can avoid the intensional fallacy indicated by Okasha.

\subsection{First Amended Argument}

We now return to the argument from externalism to the denial of KK that Okasha rejects. We ask whether that argument can be amended, when restricted to accounts of knowledge that are strongly externalist.

Okasha considers the response that the substitution is licensed by the known equivalence of $K p$ and $(B p \& p \& X p)$. He rejects it on the grounds that such an equivalence is not generally known. However, it might be known to some subject who is also a witness to externalism, and that suggests an amended version of the argument. Let $g$ denote a subject — call him 'Goldman' — who knows the correct externalist analysis of knowledge. Let $q$ be the proposition The capital of Tanzania is Dodoma. We suppose that this is a proposition that Goldman knows and believes that he knows, though he doesn't know whether that he satisfies condition $X$ with respect to that proposition. For example, if $X_{s} p$ is the condition that $s$ forms the belief $p$ by a reliable method, then we assume, following externalism, that Goldman may know that the capital of Tanzania is Dodoma without knowing that the method by which he formed this belief was reliable.

The original argument discussed by Okasha can be articulated in more detail thus:

(1) $K_{g} q \& B_{g} K_{g} q \& \neg K_{g} X_{g} q$

(fact about Goldman)

(2) $\square \forall s \forall p\left(K_{s} p \equiv\left(B_{s} p \& p \& X_{s} p\right)\right)$

(analysis of knowledge)

(3) $\square \forall s \forall p\left(\left(K_{s} p \& B_{s} K_{s} p\right) \rightarrow K_{s} K_{s} p\right)$

(KK, assumed for RAA)

(4) $K_{g} K_{g} q$

(5) $K_{g}\left(B_{g} q \& q \& X_{g} q\right)$

(6) $K_{g} X_{g} q$

(7) $\neg \square \forall s \forall p\left(\left(K_{s} p \& B_{s} K_{s} p\right) \rightarrow K_{s} K_{s} p\right)$

We amend the argument by replacing:

(2) $\square \forall s \forall p\left(K_{s} p \equiv\left(B_{s} p \& p \& X_{s} p\right)\right)$ 
by:

(2') $K_{g}\left(\square \forall s \forall p\left(K_{s} p \equiv\left(B_{s} p \& p \& X_{s} p\right)\right)\right)$

which says that Goldman knows the correct (externalist) analysis of knowledge. We then derive (5) from (4) by appealing to the closure of knowledge under known equivalence. Goldman must know a particular form of externalism, such as reliabilism-it isn't enough for him to know that externalism is true. What's more, it is important that, for the particular form of externalism that Goldman knows to be true, it is possible for a subject, such as Goldman himself, to both be a witness to externalism (if externalism is correct) and to know the correct analysis of knowledge (assuming there is one). ${ }^{15}$ For such forms of externalism, the KK principle fails. So each of this broad class of externalist analyses imply the falsity of the KK principle.

\subsection{Second Amended Argument}

In $\left(2^{\prime}\right)$, Goldman must know a form of externalism that gives necessary and sufficient conditions on knowledge (such as reliabilism), one of which is $X p$. This is what gives the equivalence and allows us to appeal to the closure of knowledge under known necessary equivalence. However, not all externalists believe that there is any correct analysis of knowledge. Such externalists, such as Williamson (2000), may hold that there are non-trivial necessary conditions on knowledge, but that these cannot be conjoined with belief and truth to provide a sufficient condition for knowledge. This leads us to seek a form of the argument that such externalists could use.

Above, we replaced:

(2) $K p \equiv(B p \& p \& X p)$

in Okasha's argument by:

$\left(2^{\prime}\right) K_{g}\left(\square \forall s \forall p\left(K_{s} p \equiv\left(B_{s} p \& p \& X_{s} p\right)\right)\right)$

Now, we replace them both by:

$$
\left(2^{\prime \prime}\right) K_{g}\left(\square \forall s \forall p\left(K_{s} p \rightarrow X_{s} p\right)\right)
$$

and derive (6) directly from (2) and (4) by appealing to the closure of knowledge under known implication. $\left(2^{\prime \prime}\right)$ says that Goldman knows that external condition $X$ is necessary for knowledge.

As above, in $\left(2^{\prime \prime}\right)$, the subject must know a particular form of externalism, in that they must know that some particular external condition, $X$, (e.g. a reliability condition, or a safety condition) is necessary for knowledge-it isn't enough to know that externalism is true. However unlike in $\left(3^{\prime}\right)$, the subject need only know that $X$ is necessary for knowledge. This makes it applicable to Williamson's version of externalism too.

\footnotetext{
15 Let us return to Conee's counterexample to KK, mentioned in footnote 1 above. Let $s$ be a witness to externalism. Conee's counterexample considers the case where $s$ has a false (and over-demanding) analysis of knowledge, and so does not believe $K_{s} p$ and a fortiori does not know $K_{s} p$. In our counterexample $s$ knows the correct analysis of knowledge: from $s$ 's failure to know $X_{s} p$ it follows that $s$ fails to know $K_{s} p$. There are of course intermediate cases where $s$ has no beliefs about the analysis of knowledge. These are the cases where, as Okasha's argument shows, a witness to externalism is not always thereby a witness to the falsity of KK.
} 


\subsubsection{What is Knowledge Closed Under?}

In the first amended argument we employed closure under known equivalence and in the second amended argument we used closure under known implication. A number of epistemologists deny that knowledge is always closed under known implication. Is our argument therefore vulnerable on that count?

We think not, for we do not need such strong closure principles for our argument to succeed. We need only that in this case-the case of the proposition $q$, that is, The capital of Tanzania is Dodoma-if Goldman knows that he knows $q$, and he knows that if someone knows a proposition then their belief in that proposition is reliably formed, then Goldman can know by inference that his belief $q$ is reliably formed (and mutatis mutandis for other reasonable externalist proposals for necessary conditions $X_{g} q$ on Goldman's knowing $q$ ).

This seems quite unlike the kind of case that leads some philosophers to reject general closure principles. Many implications that are (alleged) counterexamples to closure have the structure ( $p \rightarrow \neg q$ ), where $p$ is some proposition that we think is easily known, and $q$ is a statement to the effect that $p$ is false and, for reasons true only in a remote possible world, appearances are just as if $p$. For example, $p$ might be There is a zebra in front of me and $q$ is There is a mule in front of me cleverly disguised as a zebra. Or $p$ might be I have two hands and $q$ is I am a brain in a vat being deceived into thinking I have two hands. Although in each case I know $p$, and I know that $p$ implies $\neg q$, I don't know that the sceptical scenario presented by $q$ is false (so the objection claims). Our example doesn't have anything like that structure. In the relevant known conditional-If Goldman knows $p$, then Goldman's belief $p$ is reliably formed - the consequent proposition isn't the negation of a proposition that is true only in a remote possible world where things appear to Goldman as they actually appear here.

Consequently, the standard analyses of why closure fails (if indeed it does fail) do not apply to our case. For example, according to Nozick's analysis of knowledge, where the following tracking condition is a necessary condition on knowledge, closure fails because the antecedent can satisfy the tracking condition while the consequent fails.

If $p$ were false, $s$ would not believe $p$

(tracking)

We will write $T_{s} p$ when this holds. The tracking condition can hold for There is a zebra in front of me but fail for It is not the case that there is a mule in front of me cleverly disguised as a zebra. It can hold for I have two hands but fail for I am a brain in a vat being deceived into thinking I have two hands. And in general it can hold of a belief in the antecedent $p$ of a conditional $(p \rightarrow \neg q)$ and not of a belief in the consequent of that conditional $\neg q$ if (1) the closest $\neg p$-world is one in which the subject doesn't form the belief in $p$, and (2) the closest $q$-world is one in which the subject does form the belief in $p$ (and therefore the belief in $\neg q$ ). Both of these conditions hold for the zebra case and the hands case. What about the case of Goldman and the capital of Tanzania? The closest world in which Goldman doesn't know $q$ is one in which he doesn't come to believe that he knows it—-that is, the closest $\neg K_{g} q$-world is also a 
$\neg B_{g} K_{g} q$-world. But the closest world in which Goldman's belief in $q$ doesn't satisfy tracking is also a world in which he doesn't come to believe that he knows $q$-that is, the closest $\neg T_{g} q$-world is also a $\neg B_{g} K_{g} q$-world, and therefore a $\neg B_{g} T_{g} q$-world. That is, any route by which Goldman comes to believe $K_{g} q$ is sensitive not only to the truth of $K_{g} q$ but also to the truth of $T_{g} q$. This distinguishes Goldman's case from that of the zebra. The method by which you come to believe that there is a zebra in front of you is sensitive to whether there is a zebra in front of you, but not sensitive to whether there is a cleverly painted mule in front of you.

Now, the observations of the preceding paragraph only show that the instance of the knowledge closure principle that we need for our argument from externalism to the negation of KK is not one of the family of instances of that principle that has been questioned by appealing to sceptical hypotheses and analysed using Nozick's tracking analysis of knowledge. This does not establish that it is true. How are we to do that? First, it is worth noting that there are externalist analyses of knowledge on which the instance of the closure principle in question is false. For example, let $X_{s} p$ be the condition that $s$ 's belief $p$ is formed directly by reliable perception, memory, or testimony. Now, this is an externalist condition, if we understand 'reliable' as externalists do. And trivially that condition rejects closure because it rejects all knowledge by inference, including in the case that interests us here. However, it is an implausible account of knowledge precisely because it rejects all such knowledge. We can reject it because it radically disagrees with our intuitions about knowledge-it says that certain beliefs aren't knowledge that intuitively we take to be knowledge. And ultimately this is also how we can see that the instance of the knowledge closure principle that we need is true. The instances of the closure principle that have been questioned are questioned not primarily because they fail by the lights of a particular detailed account of knowledge, such as the tracking account offered by Nozick, but rather because they fail when tested against our intuitions. Intuitively, I know that I have two hands; and, again intuitively, I don't know that I'm not a brain in vat being deceived into thinking that I have two hands; therefore, we reject the instance of the closure principle that allows us to infer the latter knowledge from the former. By the same token, we can trust the instance of the closure principle that allows Goldman to infer from the fact that he knows $q$ to the fact that his belief in $q$ is reliably formed, or satisfies tracking or whichever other condition he knows to be necessary for knowledge, because it agrees with our intuitions.

\subsection{Internalism, KK, and the Intensional Fallacy}

The upshot of our arguments so far is that externalism does entail the falsity of the KK principle (at least in its weaker form), so long as externalism allows it to be possible for a subject to know of some strongly externalist condition that it is a necessary condition on knowledge.

In this section, we turn to the converse claim. That is, we ask whether internalismthe negation of externalism - entails KK. Okasha $(2013,84)$ reconstructs the usual 
argument for that claim as follows:

(1) $K p$

(assumption)

(2) $K p \equiv(B p \& p \& X p)$

(the analysis of knowledge)

(3) $B p$

(4) $K B p$

(3, assume $B p \rightarrow K B p$ )

(5) $K X p$

$(1,2$, internalism)

(6) $K(B p \& p \& X p)$

(7) $K K p$

Just as Okasha's reconstruction of the argument from externalism to the denial of KK committed the intentional fallacy, so does this. In this case, it occurs in the move from (6) to (7). ${ }^{16}$

Here is the argument in more detail:

(1) $K_{t} p$

(assumption)

(2) $\square \forall s \forall p\left(K_{s} p \equiv\left(B_{s} p \& p \& X_{s} p\right)\right)$

(the analysis of knowledge)

(3) $B_{t} p$

(4) $K_{t} B_{t} p$

(3, assume $B p \rightarrow K B p)$

(5) $K_{t} X_{t} p$

$(1,2$, internalism)

(6) $K_{t}\left(B_{t} p \& p \& X_{t} p\right)$

$(1,4,5)$

(7) $K_{t} K_{t} p$

Now, in order to amend this argument so that it avoids the intentional fallacy, we must replace:

(2) $\square \forall s \forall p\left(K_{s} p \equiv\left(B_{S} p \& p \& X_{s} p\right)\right)$

(the analysis of knowledge)

\footnotetext{
16 Note also that this argument requires the assumption that if an subject believes $p$, then she knows that she believes $p$. Of course, this is vulnerable to the same objection that was raised against the full KK principle at the beginning, namely, that one might believe $p$ without having considered whether one believes or knows $p$. We can fix this aspect of the argument as follows:
}

$$
\begin{aligned}
& \left(1^{\prime}\right) K p \& B K p \\
& \left(2^{\prime}\right) K p \equiv(B p \& p \& X p) \\
& \left(3^{\prime}\right) K B p \\
& \left(4^{\prime}\right) K X p \\
& \left(5^{\prime}\right) K(B p \& p \& X p) \\
& \left(6^{\prime}\right) K K p
\end{aligned}
$$

(assumption) (the analysis of knowledge) $\left(1^{\prime}\right.$, assume $\left.B K p \rightarrow K B p\right)$ $\left(1^{\prime}, 2^{\prime}\right.$, internalism) $\left(1^{\prime}, 3^{\prime}, 4^{\prime}\right)$ $\left(1^{\prime}, 5^{\prime}\right)$

Of course, this argument establishes only weak KK—-that is, $K p \& B K p \rightarrow K K p$-but that's what you'd expect. 
by:

$$
\left(2^{\prime}\right) \forall s K_{s}\left(\square \forall s \forall p\left(K_{s} p \equiv\left(B_{s} p \& p \& X_{s} p\right)\right)\right)
$$

and derive (7) from (6) by closure of knowledge under known necessary equivalence. Or, we might replace(2) by

$$
\left(2^{\prime \prime}\right) \forall s K_{s}\left(\square \forall s \forall p\left(\left(B_{s} p \& p \& X_{s} p\right) \rightarrow K_{s} p\right)\right)
$$

and derive (7) from (6) by closure of knowledge under known implication.

However, both $\left(2^{\prime}\right)$ and $\left(2^{\prime \prime}\right)$ are implausible. To show that an externalist analysis of knowledge entails the denial of the KK principle, we needed only assume that there was one subject who knew the analysis of knowledge in question and who also knew a proposition whilst not knowing that the proposition satisfied the third condition on knowledge. To show that an internalist analysis of knowledge entails the KK principle, we need to assume that all subjects know the analysis of knowledge in question. And this is clearly too much to ask.

\section{Conclusion}

While some close connection between internalism $v$. externalism and $\mathrm{KK} v$. $\neg \mathrm{KK}$ has been widely assumed, a precise argument for simple relations of entailment between these has not been forthcoming.

Indeed, the most frequently cited proposal, that externalism entails the denial of $\mathrm{KK}$, looked to be false, since it appears that there are analyses of knowledge (MM, Greco's analysis) that are intuitively externalist but which in fact entail KK. Closer inspection, however, shows that these analyses are not externalist by their own lights. That is, these analyses include a condition on knowledge, $X p$, that intuitively need not itself be known by someone who knows $p$. Yet, those analyses themselves entail that a subject who knows $p$ also knows or is in a position to know $X p$. That fact challenges both the adequacy of those analyses and their claim to be externalist. (The inadequacy of MM is obvious; the inadequacy of Greco's analysis is not.)

In the light of forgoing, Okasha's challenge, that the the most plausible derivation of a counterexample to KK from externalism commits an intensional fallacy, remains pertinent.

Nonetheless, we have shown that for that class of externalist analyses where a subject can know the analysis to be true while also being also a witness to its externalism, the falsity of KK does follow from that analysis plus the assumption that there is such a subject. The same holds for the weaker assumption that holds that there is some externalist condition on knowledge that there can be a subject who know that it is condition on knowledge. That weaker assumption is plausible, if externalism is true-it is accepted by those who deny that an analysis of knowledge is possible.

On the other hand, to construct a similar argument that a given internalist analysis implies the truth of KK, we needed the rather stronger and less plausible assumption that everyone knows that internalist analysis to correct. 
Hence, if externalism is true, then $\mathrm{KK}$ is false. And, equivalently, if $\mathrm{KK}$ is true then internalism is true. But the Okasha's argument suggests that the converse connections cannot be established.

Open Access This article is distributed under the terms of the Creative Commons Attribution 4.0 International License (http://creativecommons.org/licenses/by/4.0/), which permits unrestricted use, distribution, and reproduction in any medium, provided you give appropriate credit to the original author(s) and the source, provide a link to the Creative Commons license, and indicate if changes were made.

\section{References}

Bird, A. (1998). Philosophy of science. London: University College London Press.

BonJour, L. (1980). Externalist theories of empirical knowledge. Midwest Studies in Philosophy, 5, 53-73.

Carter, S. (2018). Higher order ignorance inside the margins. Philosophical Studies, 176, 1789-1806.

Conee, E. (2016). Review of: Sanford Goldberg (ed.) Externalism, Self-Knowledge, and Skepticism. Notre Dame Philosophical Reviews. https://ndpr.nd.edu/news/externalism-self-knowledge-and-skepticismnew-essays/.

Das, N., \& Salow, B. (2018). Transparency and the KK principle. Noûs, 52, 3-23.

Dretske, F. (2004). Externalism and modest contextualism. Erkenntnis, 61, 173-86.

Goodman, J., \& Salow, B. (2018). Taking a chance on KK. Philosophical Studies, 175, 183-96.

Greco, D. (2014). Could KK be ok? Journal of Philosophy, 111(4), 169-197.

Hemp, D. (2006). The KK (knowing that one knows) principle. In Internet Encyclopedia of Philosophy. Retrieved August 2, 2012 from http://www.iep.utm.edu/kk-princ/.

Nozick, R. (1981). Philosophical explanations. Cambridge, MA: Belknap Press.

Okasha, S. (2013). On a flawed argument against the KK principle. Analysis, 73(1), 80-86.

Pagin, P. (2012). Assertion, inference and consequence. Synthese, 187, 869-85.

Schantz, R. (2004). Introduction. In R. Schantz (Ed.), The externalist challenge (pp. 1-36). Berlin: de Gruyter.

Stalnaker, R. (2015). Luminosity and the KK thesis. In S. Goldberg (Ed.), Externalism, self-knowledge, and skepticism (pp. 19-40). Cambridge: Cambridge University Press.

Williams, M. (1995). Unnatural doubts: Epistemological realism and the basis of skepticism. Princeton: Princeton University Press.

Williamson, T. (1996). Cognitive homelessness. Journal of Philosophy, 93, 554-73.

Williamson, T. (2000). Knowledge and its limits. Oxford: Oxford University Press.

Publisher's Note Springer Nature remains neutral with regard to jurisdictional claims in published maps and institutional affiliations. 